\title{
The reinterpretation of classical art in digital format
}

\begin{abstract}
The reinterpretation of classical arts in digital art is the basic framework in which the world is moving with the help of two concepts classically and digitally. It is important to know how much digital art has helped and ease the consumption of art among the broad masses on the one hand, while on the other hand it is the classic basis for everything. The phenomena of "From pigment to pixel" is the focus of this research, or how the aesthetics of classical use are in the epoch of digital. The instrument for transferring elements from one to the other meaning system or art discourse, or as an act of creation that strategically applies to existing artistic or non-artistic creations as a building for the construction of a new artistic creation, is called appropriation. The aim of the paper is to analytically review the most important works that are the state-of-the-art in the transfer of meanings "From pigment to pixel" and to interpretively present new assumptions, synthesis and analogies that are raised from a new paradigm of observing this phenomena in the art and the technology. After a review of history in pixel-pigment implementations the paper addresses and critically discusses the works of Oliver Laric, as a representative artist that creatively interlaces the physical and digital giving new meaning to the reinterpretations of classical arts in digital forms. In the final part of the analytical review the manifestation of avatars and digital body (body and identity) are presented and discussed. In the conclusions the authors' study is summed up with three interpretative observations that give the initiative also for further researches in the field.
\end{abstract}

\author{
Marija Jevtić \\ Helena Gabrijelčič Tomc \\ University of Ljubljana, \\ Faculty of Natural Sciences and \\ Engineering, Department of \\ Textiles, Graphic Arts and Design, \\ Ljubljana, Slovenia \\ Corresponding author: \\ Helena Gabrijelčič Tomc \\ e-mail: \\ helena.gabrijelcic@ntf.uni-lj.si
}

First recieved: 5.4.2018.

Accepted: 10.7.2018.

\section{KEY WORDS}

pixel-pigment implementation, transfer of the meaning, digital art, classical art, reinterpretation

\section{Introduction}

The subject of the research is the framework of the reinterpretation that addresses two key terms - classical and digital. Even though both terms denote two strikingly different art periods that should be treated equally in the academic and research environments, the concept of classical art covers a markedly longer period of time. Therefore, classical art is too broad a notion to address and not to opt for addressing a shorter period - preferably the one in which the visual symbol (logo) emerged as a dominant phenomenon, above other hallmarks of iconography from the enormous classical heritage.

The old terminology becomes useless, so it is only logical to conclude that the heritage of the old visuals becomes harder to apply in today's chaotic time (Guga, 2012). Our research is based on classical beauty which shows a man as an ideal, a synchronicity between virtue and physical features. We are especially interested in the aesthetics of classical art and the possibility of its transfer (the popular term would be "upload") into digital form. Here is where 
we'd prefer to use the term of appropriation, or - how the classical aesthetics are used in the digital period.

We define the appropriation (and in this case, we exclusively address the definition of appropriation in art) as the transfer of elements from one system of meaning (or artistic discourse) into another. In other words - we present an analytical interpretation, which strategically and intentionally reaches out to an already existing, artistic or non-artistic works and can serve as the framework for the new artistic creation. Appropriation is a creative procedure that includes heterogeneous palette of languages, genres, techniques, media, but also the cultural requirements that go into the creation of artworks.

The concept of appropriation is a novelty in the artistic vocabulary. It was introduced in the academia through postmodernism (Buro, 2010a) during the emergence of digital platforms, networks and the expansion of internet. During the use of the internet, human body, as well as the body of art, began to settle, or the user "assimilates" into these new platforms.

The apparent similarity between the concept of appropriation and the concept of interpretation in this paper is intentional - because it is built on the alignment between two historical periods - the one which relies on pigment and the other which is defined as pixel. Both concepts, in the historical context, index diverse instances and their manifestation in modern art and culture of observing images. After all, studying the historical images, some of them from a very distant past, with the assistance of digital technologies, can be defined as the new reading of art. It brings the new insight in the complexities of classical art, which developed its contemporary scientific advances - through discovery of optics, chemistry, the philosophy of artistic aesthetics and other achievements of a particular historical era.
The idea of drawing a parallel between pigment and pixel or, respectively, discovery of linseed oil, which ushered in the triumphant development of canvas aesthetics, and Amiga 1000, which brought us the endless possibilities that come with the pixel, will vividly illustrate the complexity of the appropriation process, the reinterpretation process, and the politics of using the aesthetic material of "old" art in today's post-consumerist world. In this "brave new" age, the art becomes emancipated through on-screen, digitized images.

The aim of the paper is the presentation of the phenomena of interchangeability of pigment-pixel in the modern art and analytical review of the possible appropriation, i.e. the transfers of meaning (or artistic discourse) from one form into another. Besides, we propose some new observations about the topic, which can be presented with the framework in Figure 1.

\section{From Pigment to Pixel}

Pigment is the material that appears colored due to the selective absorption and reflection of light (Kipphan, 2001). Pigments are used as the colorants in inks, plastic and textile materials, as well as in food and cosmetic products. They may be derived from natural (organic or non-organic compounds) or artificial (chemically synthesized) materials. For example, the mineral pigments (ocher, red, green) or pigments from shells (purple) etc. In industry and art, the pigments are insoluble colorants which are typically used in the shape of powder and combined with binders (oil, glue, lacquers, eggs) and other ingredients (water). In biology, the pigment can be anything that gives color to the plant or animal cells (for example, chlorophyll, hemoglobin, melanin) (Krleža, 2015).

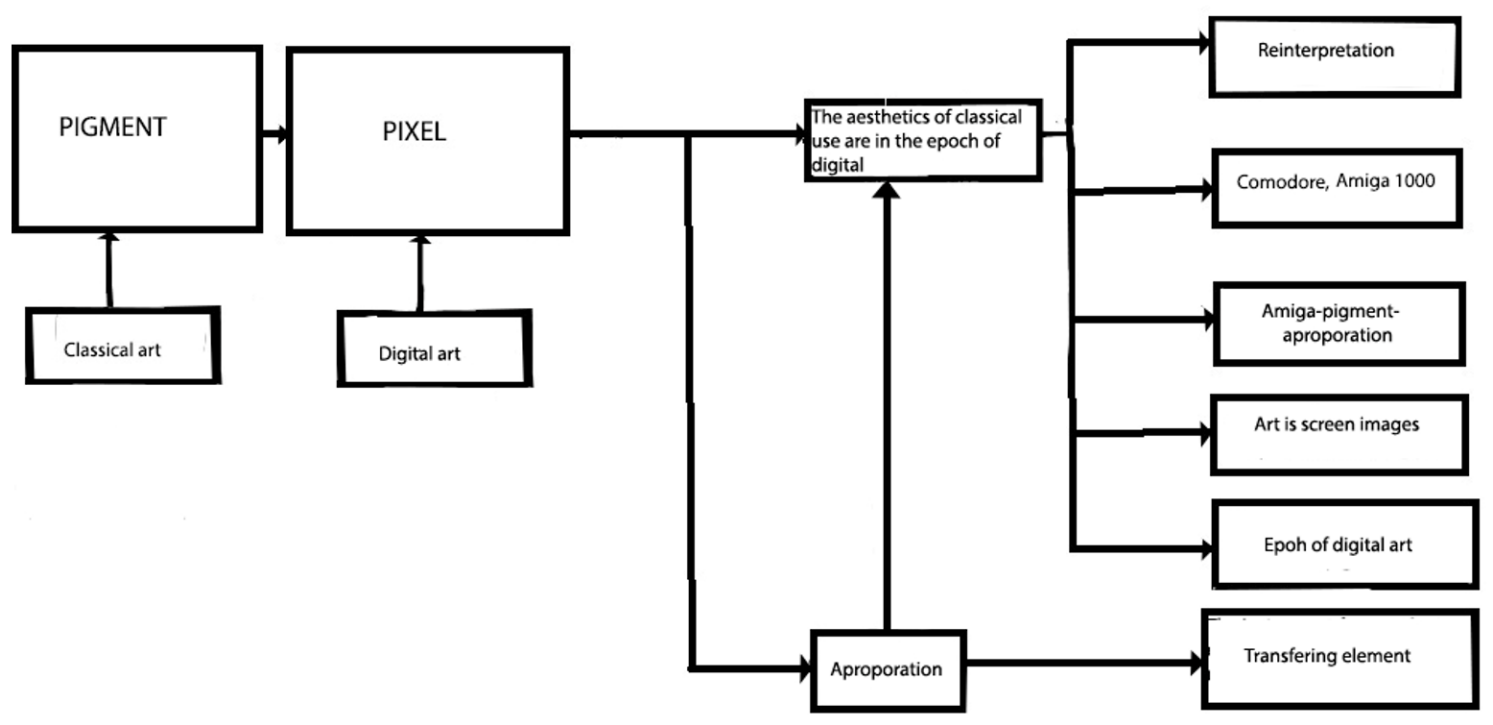

» Figure 1: Appropriation from pigment to pixel 
Pixel, a portmanteau of phrase "picture element", is the smallest element of digital picture in raster graphics, and it can be assigned different colors and other characteristics (Lyon, 2006), as is presented in Figure 2. Moreover, it can be processed (rendered) in various ways. The pixel was also the smallest addressable unit a monitor could visually represent. In the CRT monitor, the pixel is comprised of three very close dots which are red, green and blue colored, respectively. By changing the intensity of color in each of these dots, the overall color of the pixel alters. With TIF or LCD monitors, the pixels are defined in advance as miniature units shaped like squares or rectangles. Each of these are additionally divided into three surfaces that are named subpixels, that are also respectively red, green and blue colored.

Pixel (as we have established, one of many identical basic units that comprise the "mosaic" of the digital picture) and its role in the digital era, with all its elements and properties, is identical to the pigment, which has the same type of use-value on canvas (Razorback, 2014).

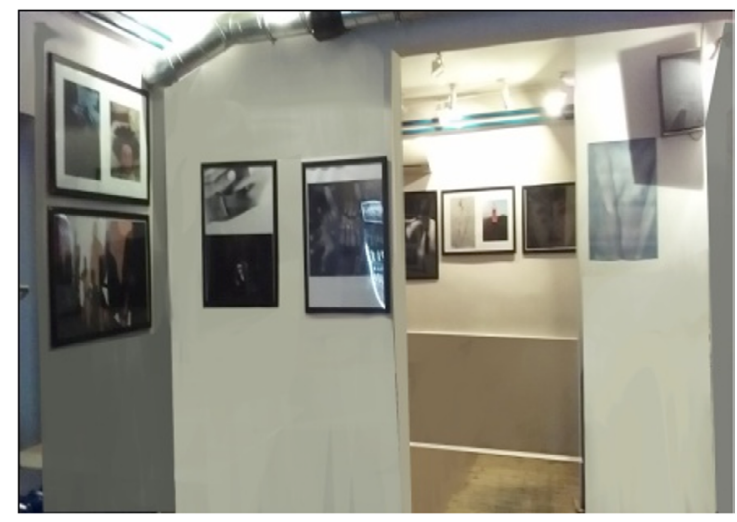

» Figure 2: The example of the representation of the pixel (digital) in the photography (physical), the showcase of digital space (image by Marija Jevtić).

The first computer, MK1, was constructed at Manchester University in 1948, and it had the capacity to store data, a seemingly simple feature that was crucial to the history of modern civilization. It was designed by F.C. Williams and T. Kilburn and constructed by Professor Max Newman. Only several years later had Ferranti, a UK electrical engineering firm, modified MK1 in collaboration with Manchester University to create the machine which served as the basis for all the subsequent commercial computers. During the postwar period, computers have become an integral part of various technological and scientific discourses, such as cybernetics, information theory, molecular biology, artificial intelligence, structuralism, etc. These ideas are still present and relevant in today's culture of new media and in addition to the discourse of art and popular culture they gave new meanings to the machines. The discussion which stemmed from this development shaped the ways in which we think about technology and the way we use it (Guga, 2012).
Memex, the portmanteau of words "memory" and "index", is the name of the hypothetical proto-hypertext system (Figure 3). It was intended for the individual use, to store and search for data as it is inherent to the human mind - by the principle of association that is comprised of speed and flexibility. The key feature of Memex would be the immediate and automatic associative connections between concepts from the ocean of diverse data (instead of selecting data by indexing). Its creator (proposer) Vannevar Bush believed the process could be mechanized. Various data, such as books, photographs, notes, etc., would be stored in the form of microfilm, with the possibility to edit that data, or to put it as example, to add new notes or comments that can be changed. This would develop the culture of exchanging that data between users. With this concept, Bush actually determined the primary characteristics of multimedia before the conditions for their realization even existed. In today's world, his ideas are embodied in several areas related to the new media (Guga, 2012):

a.) in the form of hypertext (a text with hyperlinks), or in other words, linking - which serves as the basis for internet browsing;

b.) in the way how he describes reading books or other forms of text by using Memex, we see the existing Word, PDF or similar formats;

c.) by stating that the "completely new forms of encyclopedias will appear, ready to be used with an array of networks and associative traces that are intricately interwoven, ready to be lowered into Memex, where they will be expanded," Bush has laid out the groundwork for today's online encyclopedia we all know as Wikipedia.

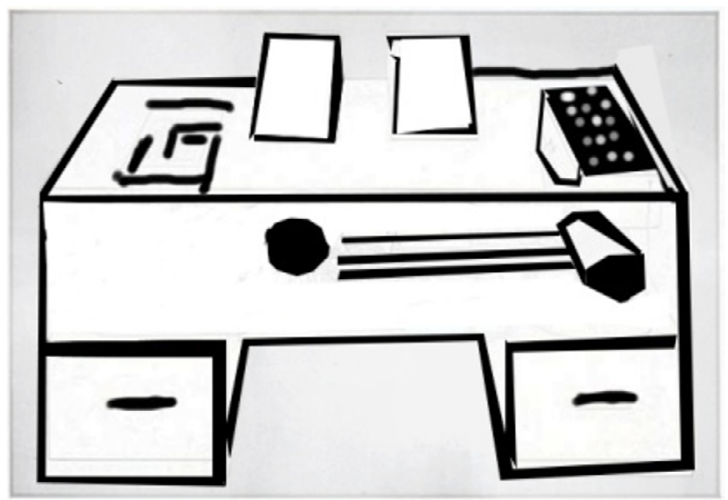

» Figure 3: Vannevar Bush: Memex, 1945 (illustration by Marija Jevtić).

\section{Digital Art}

The use of digital technologies in every aspect of our daily lives has opened endless possibilities that were hitherto unthinkable. The example of such a possi- 
bility is the instant access to information from nearly any geographical point on the planet, the multiplication of identity and its digital fluidity, as well as the reconstruction and re-articulation of the physical.

In cyberpunk literature (Guga, 2012; Knežević, 2001), the artistic practices of the new media, cyber theories, sci-fi films and graphic novels, as well as in the scientific research - we can notice the overarching phenomenon of desire to abandon the physical body and store the immortal mind into digital database where we can be whatever we want to be, whatever we want it to manifest. In relation to modern technology, the biological, physical body is often considered a secondary concern, something that is becoming obsolete. As such, it is not "equipped" to cope with the exponential rate of technological development. Therefore, it is not surprising that many studies, whether they are professional or popular, leave the problem of physicality aside to focus on the questions of identity, consciousness and "de-corporeality" in digital worlds (Guga, 2012). The art exhibition is not the end-result of the process anymore, not a "happy ending" (Pareno, 2000) but it became the place of production itself. The artist is laying out his tools for all the public to see, much in a way in which the conceptual (performance) art events were organized by Seth Siegelaub in the sixties who laid out the information at the disposal of the visitor of the exhibit.

By challenging the established concepts of art exhibition, the artists of the 1990s presented the exhibition space as a space of co-tenancy, the open stage that exists somewhere between decoration, film set and information center. In 1989, Dominique Gonzalez-Foerster, Berbard Joisten, Pierre Joseph and Philippe Parreno presented "Ozone", the exhibition that took the form of "layers of information" about the political ecology. The visitors were supposed to move through the exhibition space in such a way to create their own visual montage. "Ozone" has been offered as a "synergistic space" in which the ideal visitor would be an actor - the one who "acts out information". Next year, in Nice, the exhibition "Les Ateliers du Paradis" was presented as a "movie in real time" (Guga, 2012). Throughout the duration of the project, Pierre Joseph, Philippe Parreno and Philippe Perrin settled into the gallery space - which was equipped with the artistic works ranging from Angela Bulloch to Helmut Newton, with gadgets, trampoline, a can of Coca-Cola which moved to the rhythm of music, and selected videos. The artists moved through this space in a cyclical manner, according to a specific schedule (Burbach, 2001).

Digital art is a practice of using digital technology as the integral part of creative process. Starting with the 1970s, there have been various names assigned to this process, which include - computer art, multimedia art, digital art - however, the notion has been placed under the larger umbrella-term dubbed: the new media art.
After the initial resistance, the influence of digital technologies has transformed established disciplines like painting, drawing, sculpturing and sound design. However, these disciplines weren't transformed in the fundamental sense of the word; instead, they were further developed and a new meaning was ascribed to them. On the other hand, novel concepts such as internet art, digital installations and virtual reality became recognized artistic practices. In this case, the term "digital artist" is used to describe the artist who uses digital technologies to produce art. In broader view, digital art is a term applied to contemporary art, which uses the methods of mass production or digital media.

Lillian F. Schwartz was famous for experimenting with digital medium. She used the self-portrait of Leonardo da Vinci and compared it to Mona Lisa to create Mona/ Leo - a prime example of manipulating digital scans of famous paintings that underlined the similarities between the two. Techniques like these are used frequently in mainstream media, especially in creating commercials, as well as to produce visual effects and specific transitions in movies. Desktop publishing (DTP) had a huge impact on the publishing industry, although this is more related to the graphic design. Digital and traditional artists use multiple sources of electronic information and programs to create their work. Digital art can be fully computer-generated imagery (CGI), and these include fractals and algorithmic art, as well as scanned photographs or images drawn by using vector graphics of a particular software with the help of mouse or digital drawing tablets (pads) (Burio, 2011).

Commodore hired Andy Warhol in 1985 to produce several works that were meant to serve as a promotion of the computer Amiga 1000. It was through that many of the works had been lost. However, Cory Arcangel saw Warhol's video presentation of Amiga on the Internet, and subsequently visited the museum archives to discover if the famous artist has done something else for Commodore. When he received a pile of floppy disks, he called the computer department of the museum to help him out. This is how Andy Warhol's lost computer art, a benchmark for the history of digital art, was rediscovered thirty years later. Celebrities of such a large caliber, such as Andy Warhol and Debbie Harry actively participated in presenting the artistic possibilities of the new machine and brought a completely fresh approach to the method of marketing a new technology (Rakić, 2014).

The computer generated visual media, the computer art, the procedurally generated photorealistic landscape created through Terragen program - a scenery generator developed by Planetside Software - is used to create CGI for films. Digital visual art consists of any 2D visual information that is displayed on electronic video device, or translated into 3D information, projected through the electronic device. The simplest of these 
is, as we could well presume, 2D computer generated graphics - which show how much the artist is able to draw by using merely pen and paper, or, in the context we are addressing, by using either the electronic mouse or drawing tablet (pad), as presented in Figure 4.

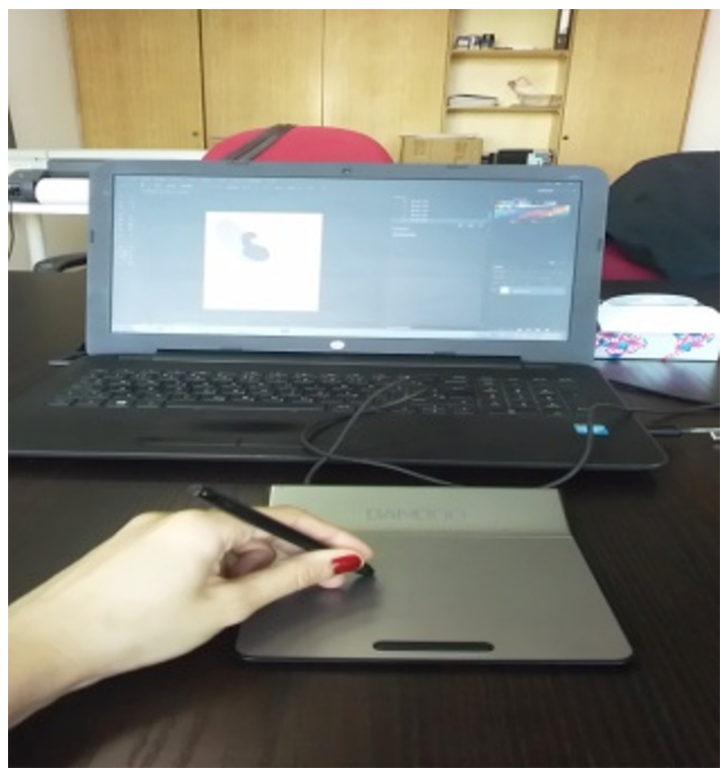

» Figure 4: Drawing pad (Photo by Marija Jevtić).

What the observer can see on screen appears as if it has been drawn with a pencil, brush or other established tools. Another type of 3D graphics shows the virtual space on screen, and objects appear as if they are "leaving the monitor". For 2D computer graphics, typically, raster graphics are used as the primary means of data source representation, whereas 3D computer graphics uses vector graphics to create vivid virtual installations of reality.

The third paradigm is the creation of $2 \mathrm{D}$ or $3 \mathrm{D}$ computer graphic entirely through the execution of algorithms written in computer programs. These visual representations can be considered "artworks" of computers. It is impossible to produce them otherwise, and the most well-known examples of such art pieces is fractal art, as well as datamoshing, i.e. manipulation of the media data in order to achieve visual or auditory effects and algorithmic art (Jovanović, 2009).

Gopakumar R. P., an Indian digital artist, is a great proponent of digital art installations - a broad filed of activities that can contain many shapes. Some of them resemble video exhibitions, displayed in large scale, and which include projections and live video feeds from the web-cameras. The projections are, in the best of circumstances, made with technology that enhances the visual impression and creates an impressive environment for the audience (Tallant, 2016). Other artists dare to go even further and try to ensure total immersion into the virtual space. This type of the installation is usually site-specific, without fixed stability and without fixed dimensionality, which means they can be readapted into a space completely suited to the artist's needs.

\section{Digital Art, Digital Image}

Soon after the Macintosh was released to the public, Microsoft began to design their own operative system called Windows, with intention of rendering MS-DOS insignificant (IBM machines worked on MS-DOS up until that point). With the help of WIMP system (windows, icons, mouse, pointer) everyone could use the PC with ease. Its multi-functionality, combined with the user-friendly interface, contributed a lot to the integration of the computers into all fields of human activity. Complete opposites of the cold and unappealing military computers which were too complex for casual interaction, the PC was constructed as a subtler, "humanized" machine that announced the beginning of the new commercial development. It became an epitome of the mass media technology and, on a deeper level, its widespread use implied the fundamental changes in the one-sided relationship between the man and the machine (Buro, 2010a). The showcase of this integration is one of many possibilities in using digital tools to draw and paint with Microsoft Surface, a sophisticated new offshoot from the line of Microsoft products. This machine shares all its characteristics with a regular Microsoft computer, but, with additional design changes that has brought it closer to the similarities with regular canvas. The application of this tablet is multi-faceted. It can be used in movie industry, animation production, etc. It is the first Microsoft PC to introduce this entirely new concept of "all-in-one" technology in such a palpable way. With the improved interface and array of colors, and equipped with the better lightning options, this device is created with designers, artists and architects as its primary users in mind. By using this screen-tablet, the artists have the same accessible tools to create works with artistic merit, and to exhibit them in different contexts. These artists would then scan and format digital material into 3D, but not before drawing it in 2D first, which is the cornerstone of this digital process.

\section{Digital Picture-Video (the examples of movies with special effects)}

With the fusion of new media and art, a step forward has been made in relation to the practices established during the avant-garde artistic movements. The element of the PC is brought into the dynamic as, basically, a third party. Interactivity becomes a far more complex notion when compared to the possibilities presented with previous, traditional media forms. "We are not in 
Kansas anymore," said Dorothy to her dog Toto when they ended up in the extraordinary new realm known as $\mathrm{Oz}$ in the renowned novel "The Wizard of $\mathrm{Oz}$ " by Frank L. Baum. With the same sentence, the colonel Miles Quaritch (player by Stephen Lang) addressed the newly arrived soldiers to the planet Pandora, in the film "Avatar" directed by James Cameron (Jovanović, 2013).

\section{From Pigment to Pixel, From Classical to Digital}

Oliver Laric is the great admirer of plaster. Therefore, his exhibition "Photoplastik" transforms the Secession's main hall into a sculpture display (Figures 5-6).

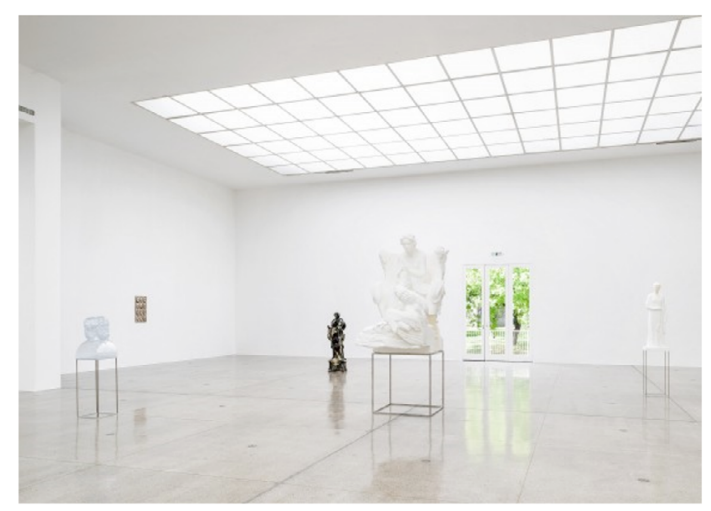

» Figure 5: Oliver Laric, "Photoplastik" installation, Secession, 2016 (Approved by the author of the work Oliver Laric).

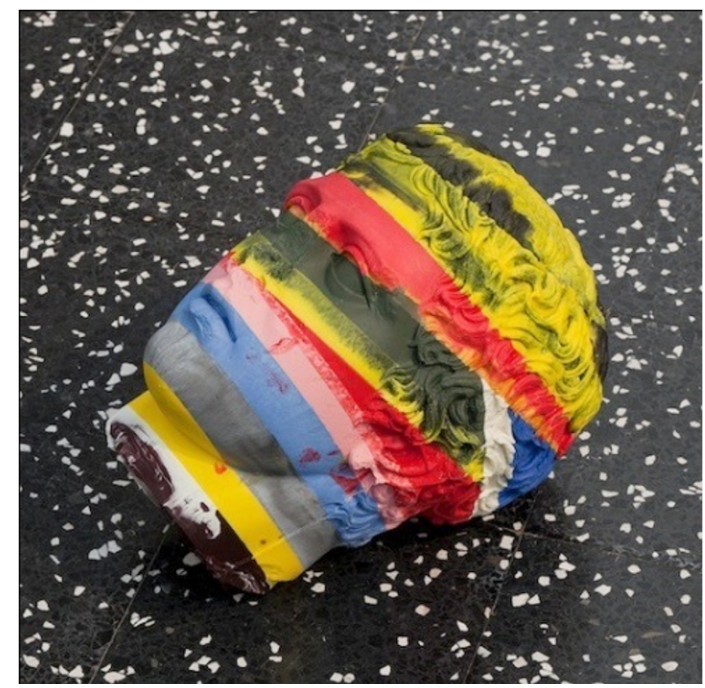

» Figure 6: Oliver Laric, "Kopienkritik", Skulpturhalle Basel, 2011 (Approved by the author of the work Oliver Laric).

The exhibition showcases his work, as he reaches out to other artworks from antiquity to the present, and mesh- es them with the objects drawn from pop-culture and natural sciences. Designed specifically for the Secession, it consists of entirely new works; most of them are 3D rendered prints, a product of the technology that has been central to the artist's occupation in the last couple of years. The selection of sculptures may appear bewildering at the first glance, but with apparent ease, Laric combines and transfers qualities from the digital domain - such as convenient reproducibility, endless variability, and rapid multiplication - into physical space. As the result, we get material sculptures which are based on scans of artworks and other objects. Laric worked the University of Vienna's Institute of Classic Archeology (ger. InstitutfürKlassischeArchäologie) (Laric, 2011; Laric, 2016).

The molded sculptures are only one of several components that function independently from one another, but constitute the entirety of the exhibition project. The second, and not any less important component, consists of data gathered from the sculpture which are available to be downloaded. It has been widely publicized that Laric took projects in collaboration with Lincoln Museum in England, in 2012.

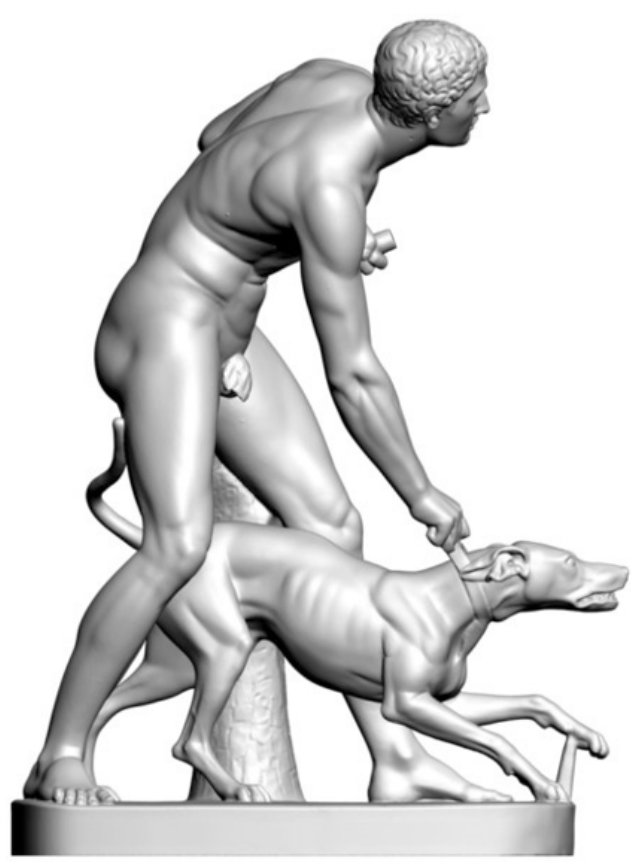

» Figure 7: Oliver Laric, "Linkoln 3D Scans", 2013

(Approved by the author of the workOliver Laric).

It marked the beginning of a bigger effort to, by consulting and cooperating with a string of prominent museums, work on assembling the 3D archive of important artworks, shoulder to shoulder with everyday objects. Over the past several years, the negotiations about the general access to the objects in these collections (and their availability to use in other artistic works and montages) have inescapably become the part of the artistic practice. Laric's efforts to expand upon the number of 
artworks that are kept in the museums across social and cultural borders, and beyond various longitudes and latitudes, have a goal to increase their accessibility to the digital community (Laric, 2018). The name of the exhibition is a reference to the book of Viennese scholar that studied the history of photography, Eduard Kuchinka - the book entitled "Die Photoplastik" (Laric, 2018).

The selection of works included in the exhibition show how Laric intertwines his research of history and technology, by combining technological basis of 3D printing, along with artistic, formal and archeological interests. His juxtaposition of works that harken from different epochs sometimes point to the methodology in both history and art. He is especially interested in the afterlife of the antique times and how it affected European culture. Digital sculptures like "copies" provoke the questions of authorship, Laric - whose earlier work dealt with the notion of dogmatic- has cast it aside (Laric, 2018). The Roman sculptors just copied the Greek role-models and never created anything particularly original - is just one of the examples he had used to make his artistic argument (Laric, 2018).

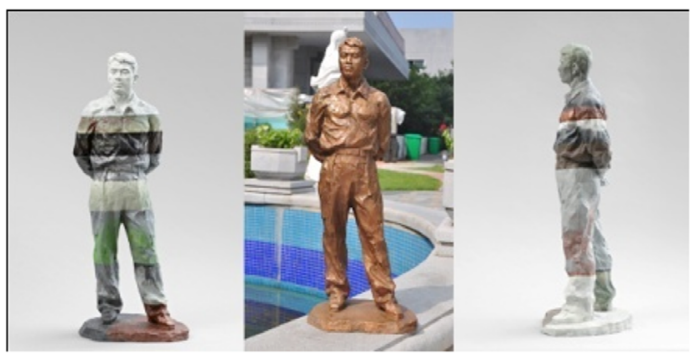

» Figure 8: Oliver Laric, "Mansudea Overseas Project Pyongyang", 2013 (Approved by the author of the work Oliver Laric).

Hermes fastening the sandal, from the collection done with plaster, and in the ownership of the Institute of Classic Archeology at the university of Vienna (ger. Institut für Klassische Archäologie), is one such example that focuses on the work from Roman times that heavily borrows, or to be blunter - copies, from the Greek source. The popular sculpture can be found in countless versions and interpretations. The difference of posture on the given examples showcases the way in which the subjective preferences have, along with the shifting trends in fashion and taste of a particular time, influenced the artist to offer his own interpretation. In the exhibition, it appears in front of the statue from the park Schonbrunn Palace, which represents a roman nobleman and a politician. However, the one noticeable difference is the fact that the statue in question was covered with clothes, but the similarity to Hermes was unmistakable (Laric, 2018).

Related to the numerous animal sculptures, the so-called "play-scupture" which dates from ninety fifties and ninety sixties, offer an interesting insight into the cultural politics of Vienna during the last "economic boom". In contrast, "Polar Bear" (1902) by Alfred Kubinshows the predator during the hunt, has an overt aim to emulate the scientifically informed realism which has little to do with Kubin's later anima figures (Leighton, 2018). The statue of Saint Veronica, the second public work, is made of synthetic resin for the exhibition. The black and white marbling imitates the natural stone, which is assembled with the layers of resin, and it can be interpreted as the metaphor for the gradual transformation in the iconographic tradition. Laric found Christ Sudarium to be very interesting as an example. The sculpture, or the painting, hasn't been done by human hand. The artist, therefore, demonstrably poses the question of material and its symbolic meaning. The artist's booklet, published in the conjunction with the exhibition, and which was also called "Der Fotoplastik", contains detailed information, including the links to download all the works themselves, as well as supplementary materials and additional sculptures which Laric scanned while he was preparing the exhibition. It includes a sort of a timeline outlook of 3D technology, starting with Francois Villemi in 1860s, and up until the presumed global market of 3D scans in 2020. Moreover, it includes the gallery of different renders of Beethoven statues, and online corrections and discussions about copyright infringement and other sensitive topics related to internet rights (Laric, 2018).

The art of Oliver Laric is deeply rooted within the postmodern topic of "questioning the ownership". With his work, throughout the years, he was not only interesting and provocative, but he was also through-provoking, fun, witty and even humorous on occasion. He basically created a new modern genre - the critic of copies (Laric, 2018). Laric has introduced many advantages with printing of 3D sculptures from antique period, a bona fide contribution to art. In 2012 he won a prestigious annual award for modern art. Per his suggestion, the 3D scans for the archives of Usher Gallery have been rendered (Figure 9).

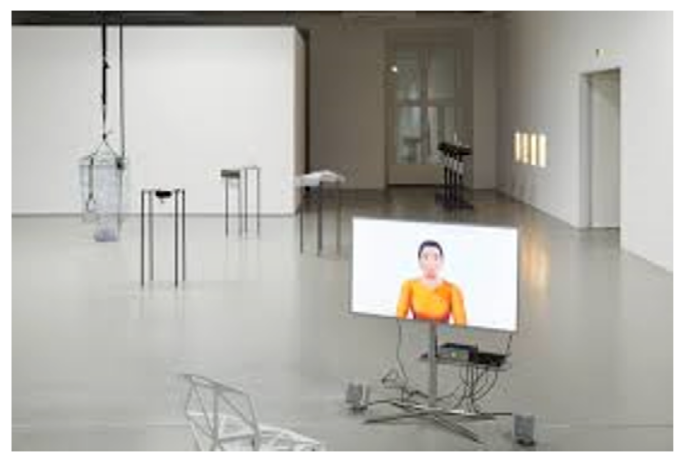

» Figure 9: Oliver Laric 5, "One Channel HD Video", 10 minutes, 2013 (Approved by the author of the work Oliver Laric).

Laric's 3D scanning project includes 3D models, some of his scans have existed in varying textures and color. He 
even included other sections of his works, diverse and exciting, the central concept lies in the topic of questioning authorship and authenticity, just like with the examples mentioned above. The public is encouraged to print the copies of their own object and trinkets, and/ or to manipulate them in the software in countless digital ways and variations. The museum has given carte blanche to Laric when it comes to expressing creative freedom in 3D itself, and all of those works and variations can be downloaded from the website of the museum. In Figure 10 "Rendering of Einstein" is presented, where 3D scans are offered to the public to download.
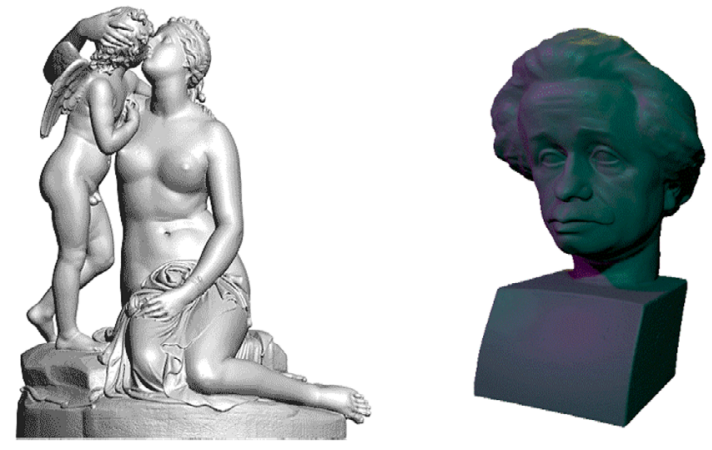

» Figure 10: Oliver Laric, "Rendering of Einstein", by Matthew Williamson, from Lincoln 3D scans offered to the public to download. (Approved by the author of the work Oliver Laric).

"The Version" (2010) is the HD channel of Oliver Laric that accounted for a whooping number of seventy variations throughout the duration of the project, the video clips show the religious figures with the accent on discourse about the Greek influence on Roman sculptures.

By determining the image, overall and by type (body build) as well as by the shape of the body, Laric creates the visual essence of the image, the image as the identity of the past. Laric removes the focus from the original copies and remixes, but he does not take away the importance, only intending to create a flow.

"Touch My Body" (Green Screen Version), was another project that included Oliver Laric; i.e. digital video of Mariah Carrey for the song "Touch My Body" was shot by Laric with the group of artists, as they painstakingly removed the green background to have only Mariah Carrey in front of the blank (and crucially, malleable) background.

The video has been uploaded to YouTube, and it has been made available to all users to manipulate the background with their own video or photograph, and therefore create their own version of the music video. With his work, Laric does not only create his own art pieces, but he also provides the artwork that is interactive and refreshing. It includes the reflection of "visitor" /"spectator", a person that can have his or her own creative input (Laric, 2018).

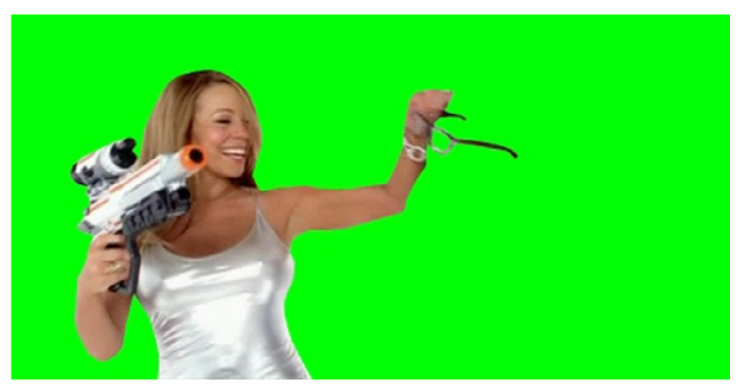

» Figure 11: Oliver Laric, "Mariah Carrey in front of the blank (and crucially, malleable) background" (Approved by the author of the work Oliver Laric).

\section{The Social Networks and the Transition to Digital}

In today's public discourse, we have seen the ubiquity of all-encroaching autonomous machines, the topic of privacy, the reign of algorithm, internet security, social and ecological influences that the new technologies have on our lives. In a world of ever-expanding technological development that has acquired the rhythm of geometrical progression, humans have found themselves surrounded by the myriad of technical and social challenges. The need to question the society and technology arises.

The usage of internet represents a commonplace in the life of everyman in the 21stcentury. The internet can be used as a platform to acquire information, to get a job, to be updated with a pre-selected type of marketing material, to communicate with the family, friends and people separated from the user over insurmountable distances. It is empirically safe to state that the internet is the most dominant medium of our time. Some of the most frequently visited web pages are so-called social networks like Facebook and Twitter. The reasons for this lie in the intrinsic need of the people/users to communicate, not to mention- bid for attention and upload their own photographs (Todorović, 2009).

Using the social networks is free, every person connected to the internet can create their own account without having to reimburse anyone. On that basis alone, one can get the impression that the social network represents something that completely resists the general global tendency toward the ideology of neoliberalism. At the first glance, it seems as if the companies behind social networks do not generate any profits. Howev$\mathrm{er}$, in the following analysis, we will try to show that social networks are nothing if they are not the "cooking pots" for the reproduction of neoliberal ideology, or the flow of capital. A French Marxist philosopher Louis 
Althusser, in his essay "Ideology and Ideological State Apparatuses (Notes towards an Investigation)", differentiates between so-called "state ideological apparatus" and "state repressive apparatus". While the repressive apparatus includes the army, the police, the judiciary and similar institutions, the ideological apparatus includes institutions primarily related to education, religion, information and culture (Todorović, 2016).

Social networks also serve as a platform for something very fundamental - they have the function to "reproduce" identity, and give us the opportunity to exists in several places at once - at the same time our body exists in the digital world and in the real world, not to mention the fact there's a possibility to have several identities in the virtual world. When the body ends up in the space of social networks, and therefore in the virtual space that can be observed over the monitor, we can freely call that phenomenon - the body in digital space. In this case, if the subject finds himself/ herself somewhere in the nature, committed to various outdoor activities, someone on the social network can view the subject's profile. This is also one of the examples of nearly pathological narcissism, or in softer terms, at least the example of self-addiction (Figure 12).

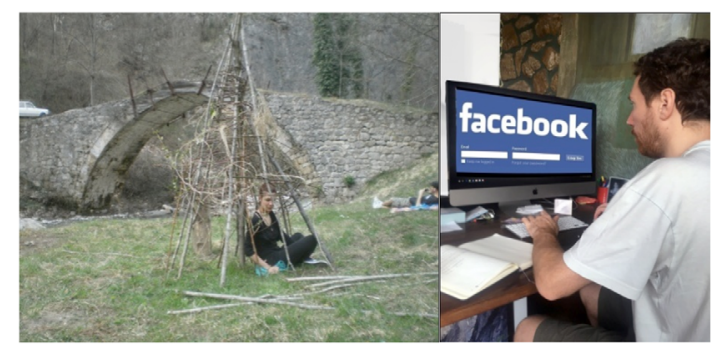

» Figure 12: Physical vs. digital (Photo of Marija Jevtić).

For contemporary artists, the participation in the emergence of "culture of activity" forms the surrounding that materializes these narratives. Represented and hidden in all cultural products, as well as in our daily environment, these narratives reproduce social scenarios that are generally acknowledged: the cell phone, a piece of clothing, the accolades and special thanks in television shows, the logo of the company, all of these encourage a particular behavior and promote collective values and visions of the world. (Buro, 2010b).

\section{Avatars}

In the movie "Avatar" (Wilhelm and Mathison, 2009), we are faced with two distinct realities. On the one hand, there is a run-of-the-mill world of imperialist colonialism filled with cold, gray machines. In it, the people are working on sophisticated, high-end computers which do not possess a material quality. They are more akin to the hologram or a 3D projection (Jastratijević, 1980).
These computers allow the entire scanned, virtual copy of the world of Pandora to be placed on a regular (still futuristic) office desk. Through this hologram, one can easily "move" the environment with a casual wave of hand. On the other hand, there is a wonderful, lush realm of Pandora natives that live in almost incestuous relationship with nature. In order to illustrate some kind of connection between classical and digital art, a parallel between nature and avatars can be pointed out.

Na'vi serve nature as a deity, all the while, ideological apparatuses of the Earth lead their subjects directly to its/their death. Throughout the entire film, the writer, director and lead producer James Cameron is trying to draw a clear condemnation of the entire military-industrial machinery.

In other words, the interaction with the new media artwork include corporeal, sensory, emotional and intellectual activity which is mediated by the machine. The mechanical apparatus in question serves as a kind of prosthesis, a person's supplement, an extension or a third party that is necessary for the interaction between the subject and the artwork to even occur. It is a necessary framework for that additional perception. In addition, artists are not limited solely to the usage of technological elements in their realization and presentation of artwork. They have stepped into other scientific areas that constitute our daily reality - these come from the areas of biology, genetics, ecology, medical research, physics, earth science, robotics, telecommunications, research of artificial intelligence, various informational techniques of visualization and research into physical-sensory computer interfaces (Buro, 2010b). These various topics and factors that bombard the artists today only intensified the dialectical relationship and created a symbiosis between science, technology, art and everyday life. Research, intervention and re-composition has been made at the technological level, but the approach to the biological material is done in the same way: given to us by nature, a sort of a constant throughout all of the civilizational changes, it is now regarded as something that is open to further development, reconfiguration, grafting and transformation. By delving into such diverse areas, the new media art has become inseparable from scientific and technological research, and now it includes a wide field of action: internet art, software art, virtual art, art in the area of telerobotics, telepresence, bio-art, genetic art, etc. As such, the new media art is heterogeneous hybrid of fields of research and it requires an interdisciplinary approach, for a simple reason that it broke out of the confines of art history and fused it into unbreakable relationships with various scientific disciplines (Krleža, 2009).

Computers, internet, cell phones, 3D Cineplex, interactive television and VR spaces all share the characteristics of three-dimensional images, and they had 
a strong influence on the perception and the reception of various forms of artworks, not only as physical-physiological process, but also as a cultural one.

When the man's consciousness is connected to the machine, the body of a new being springs to life. This being can move and use the brain of a man, it's subjected to him. However, only a single click is sufficient to sever the connection and avatar becomes only a pile of genetic material (Krleža, 2009).

Žižek even states (Krleža, 2009) that the Na'vi tribes, in fact, do not have much of a choice considering the situation they were put in by the director James Cameron. They will either be victims of harsh imperialistic reality, or they will play their part in the fantasy of a white man. It essentially doesn't matter if they are saved or destroyed in a crucial context of them being merely a toy in the hands of humans. After the fantastic trip to the land of $\mathrm{Oz}$, the little girl Dorothy decides to leave this colorful realm (both figuratively and literally) and return to the black and white world of Kansas. Why? Because, as she repeats several times as a mantra in the film, "there is no place like home". Jake Sully, (Krleža, 2009) on the other hand, rejects this mundane reality and refuses to return to it. He is adamant it is not the only real world that exists. He sends a message that there is a possibility the home, actually, is not the best place. The only question that remains is this will be interpreted as the action of a desperate man, or the final moment of transcendental self-realization.

\section{Body and Identity, Digital Body}

The question of identity is one of the key themes that runs through many different but interconnected discourses on cyberspace as a technologically mediated digital environment in which, with the emergence of Web 3.0 platforms for the communication and interaction of users, the concept of identity literally became a matter of freedom and choice, no imposed and/or fixed meanings. Disembodied in the endless fields of data, identity becomes completely malleable. The representation of physical appearance can be selected and modified at will. By changing physical attributes, the nature of interactions is changed too, which does not necessarily affect how we perceive and define ourselves (Razorback, 2014).

Whether it is through capturing movement, live rendering of graphics, animation or other modes of data visualization, the body is a reference and inspiration for many artists of various digital media, the artists that work with interactive technology. The body, identity and interactive medium are all part of the research into this confluence, looking through multiple lenses to explore the body and identity we can nearly gleam into a technological evolution, and for once, at least hope to see it clearly. As we inhibit the bodies of digital origin, we ask the technology to break us out of social confines (Guga, 2012).

That's when technology captures the kinetic energy and our ego is lost in the process. Through dynamic works of Luftwerk, as well as "synchronous objects" created by William Forsythe, we hope to bring out the research ideas that pervade our perception of the body and impulses to move beyond it, in the unmarked cyberspace. This panel discussion will explore the body when we investigate through conjoined performance capabilities and technology (Guga, 2012).

The video game that broke away from such established structures and brought in a complete new representation and perception of female "avatar" was "Lara Croft: Tomb Raider" in which the protagonist, or avatar, is a female archeologist and adventurer called Lara Croft. Created as a complete opposite of the stereotypical female representation mainstream has accepted until then (and when I write "mainstream" it relates solely to then underdeveloped video game culture), Lara Croft became a forefront of the challenging gameplay even for the experienced players, and despite her gender. Since the game "Tomb Raider" appeared on the market in 1996, the popularity of Lara Croft flowed out of the gaming culture and over the heads of fans that enjoyed playing it obsessively - she became a true multi-platform character. She turned into a globally renowned "personality" and a true icon for the digital age. The creator of Lara Croft initially planned to implement a male protagonist it no the game into "Tomb Raider". However, because of the uncomfortably noticeable similarity the character bore to iconic Indiana Jones, he reasoned to put a female protagonist in his place, an action that would hopefully offer something original and never seen before (Guga, 2012).

\section{Conclusion}

Through the analysis presented in the overview and analytical interpretation, we proceed to make a conclusion that is based on three points:

- Digital art revivified classical art, the artists delving into digital art often make homages to classical art, celebrating its heritage and saving it from sinking into irrelevance. The classical works are subsequently placed in a new kind of space, a digital space which is the uncharted territory, thus casting a new, fresh light on the old artworks. Instead of linseed oil and pigments, the artist uses computers, software and equipment for digital printing and modelling.

- Art in the digital format is no longer trapped on canvas. It is placed on a screen, available to everyone, and moreover, everyone has an option to be an artist in a way, to develop and extend it accord- 
ing to their own feelings and whim; effectively, to have an interactive relationship with the artwork. - Art is revivified in the truest sense of that word, digital design reached every element of the artwork creation, and it therefore affects the essence of humanity in a crisp way. It creates a virtual world and representation that can basically be called artificial intelligence - the man connected to the machine, akin to avatars and cyborgs. These avatars can be anything we want them to be - they have sprung out of man's imagination, and they can inhibit any world we can now program based on our "real" experiences.

\section{References}

Amiga. (2014) How "Komodor Amiga" was made by a computer artist by Andy Warhol. Available from: https://www.vice.com/rs/article/z4n95y/kako-je-komodor-amiga-napravio-kompjuterskog-umetnika-od-endija-vorhola [Accessed 23rd november 2017].

Ančić, I. (2014) Creative aspects of the published artistic digital painting. Belgrade, University of Arts in Belgrade Interdisciplinary Studies.

Burbach, R. (2001) Globalization and Postmodern Politics, 1st Ed., Pluto Press, p. 176

Buro, N. (2010a) Postproduction, as a screen to reprogram the art world. Trans. Faculty of Media and Communications, Belgrade.

Buro, N. (2010b) Rational aesthetics. Trans. Faculty of Media and Communications, Belgrade.

Guga, J. (2010) Body, Identity in the Digital Space, PhD Thesis, University of Arts, Belgrade.

Jastratijević, I., (1980) Study of fashion, signs and meanings clothing practices. Belgrade, Orion Art.pp. 20-31.

Jovanović, T. (2009) Extensions of the body in the age of global war. Propeller\#1. Available from: http://propeler.fmk.edu.rs/?p=1 [Accessed 12th February 2017].

Jovanović T. (2013) Cyborg aesthetics, fash-

ion and communication. Propeller\#6. Avail-

able from: http://web.fmk.edu.rs/Propeler/6. pdf [Accessed 12th February 2017].

Kipphan, H. (2001) Handbook of Print Media. New York, Springer Science \& Business Media, pp. 68-113.

Knežević, B. (2002) Android's Premonition. Belgrade, Boban Knežević publishing house, p. 502.
Krleža, N. (2009). Planet Pandora, Avatar as the Return Home. Master studies, Digital Arts and New Media, Faculty of Media and Communications, University Singidunum.

Laric,O. (2011) Kopienkritik (curated by Raffael Dorig), Skulpturhalle Basel. Available from: http://www.tanyaleighton.com/index.php?page$|d=425 \&|=e n /$ [Accessed23rd november 2017].

Laric, O. (2016) Seventeen gallery. Available from: http://www.seventeengallery. com [Accessed23rd november 2017].

Laric, O. (2018) Oliver Laric website. Available from: http://oliverlaric.com/ [Accessed 12th december 2017]

Leighton, T. (2018) Tanya Leighton. Available from: http://www.tanyaleighton.com/index.php?page$|d=425 \&|=e n$ [Accessed 12th December 2017]

Lipovicki, Ž. (1992) The Empire of Ephemeral. Novi Sad, Publishing house of Zoran Stojanović..

Marković, M. and Jovanović, T. (2012) Moving pictures. Propeller\#1. Available from: http://propeler.fmk. edu.rs/?p=1/ [Accessed 12th February 2017].

Miladinov, M., Todorović, I., Jevtić, M., Milenković, V. (2016) Modern Reading of Technology. Novi Sad, Institute for flexible culture and technologies - Napon.

Razorback, F. (2014) Chapter 3: Perspectives. OpenGameArt.org. Les Forges Pixel Art Course. Available from: https://opengameart.org/content/chapter-3-perspectives [Accessed 14th Fabruary 2017].

Tallant, S. (2016) Rita McBride. Available from: http://www.biennial.com/2016/exhibition/artists/ rita-mcbride [Accessed 12th december 2017].

Todorović, L. A. (2009) The Art and Technology of Communication. Belgrade, Clio.

Wilhelm, M. and Mathison, D. (2009) A Confidential Report on the Biological and Social History of Pandora. In: James Cameron's Avatar. Harper Entertainment, London.

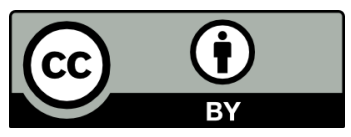

(C) 2018 Authors. Published by the University of Novi Sad, Faculty of Technical Sciences, Department of Graphic Engineering and Design. This article is an open access article distributed under the terms and conditions of the Creative Commons Attribution license 3.0 Serbia (http://creativecommons.org/licenses/by/3.0/rs/). 